\title{
o CONSUMO DE PRODUTOS DE MODA VISTO A PARTIR DE EXPERIÊNCIAS DE ÓCIO
}

The consumption of fashion products seen from leisure experiences

\section{PINHEIRO, Natália Parente}

Universidade de Fortaleza I nataliaparentep@gmail.com

\section{MATOS, Cynthia de Holanda Sousa}

Universidade de Fortaleza e FANOR DeVry - Br I cynthiasousa@terra.com.br

\section{LOPES, Humberto Pinheiro}

Universidade de Coimbra I umpiro@gmail.com

\begin{abstract}
Resumo
Este artigo busca problematizar a associação entre o consumo de produtos de moda e a vivência de momentos de ócio, uma vez que estas atividades apresentariam como semelhanças o restabelecimento de forças gastas nas atividades laborais. Foi feita uma revisão bibliográfica explorando os temas propostos, a fim de possibilitar a associação tomada como hipótese. Percebese que a semelhança entre os sentimentos contemporaneamente vinculados a estas atividades possibilita a associação.
\end{abstract}

Palavras-chave: Ócio. Consumo. Moda. Trabalho.

\section{Abstract}

This paper intents to problematize the association between the consumption of fashion products and the experience of leisure time, since these activities would present similarities as restoring forces spent in work activities. A literature review was conducted by exploring the themes proposed in order to allow the association taken as hypothesis. It is noticed that the similarity between the feelings contemporarily linked to these activities enables the association.

Keywords: Leisure. Consumption. Fashion. Work. 


\section{INTRODUÇ̃̃O}

Ao compreendermos o aspecto subjetivo para a caracterização de experiências prazerosas e reestabelecedoras de forças gastas nos momentos de trabalho, supõe-se que o consumo de bens e de serviços figure entre as principais atividades eleitas para os momentos de não trabalho, fazendo com que se tornem atividades predominantes na cultura contemporânea. Com isso, pressupõe-se que a vivência de experiências de ócio possa ser associada ao consumo de produtos de moda.

Uma aparente contradição, ao se associar o ócio e o consumo, é somada a tantas outras que pairam sobre o mundo da moda. Por exemplo, a moda pode servir de diferenciador social, ao mesmo tempo em que tenta uniformizar, através das tendências, mesmo em meio a um universo de escolhas. Estas e outras contradições são geralmente superadas pelas características inerentes à sociedade contemporânea, discutidas ao longo do texto.

A partir de uma noção histórica e do contraponto entre as esferas ócio versus trabalho e consumo versus produção, discutimos a possibilidade de associação entre eles no sentido de possibilitar uma percepção da vivência do ócio na contemporaneidade, visto que esta associação possibilita discussões a respeito da mudança de significados, considerando as características sociais contemporâneas como diferentes daquela na qual o conceito foi criado.

\section{ÓCIO E TRABALHO}

A palavra "ócio" pode ser compreendida a partir de significados distintos, de acordo com a cultura e o momento sócio-histórico no qual se constitui cada significado. Na Grécia antiga, o ócio, segundo Pinheiro, Rhoden e Martins (2010, p. 1134), "representava um valor nobre de vida educativa e contemplativa, um ideal de sabedoria".

A partir do século XIX, o significado de ócio tomou proporções diferentes daquelas vistas na Grécia antiga, passando a ser associado à "vadiagem, libertinagem, improdutividade" (PINHEIRO; RHODEN; MARTINS, 2010, p. 1134), ou seja, o indivíduo que vivenciasse momentos de ócio estaria à margem da sociedade.

Ócio, então, passa a ser associado à preguiça. O preguiçoso, como dispõe Novaes (2012, p. 12), comete um "pecado capital", pois "Pela lógica do mundo do trabalho e da Igreja, o preguiçoso deve, portanto, sentir-se culpado e pagar pelo que não faz" (NOVAES, 2012, p. 12). Ainda hoje, uma parte da sociedade encara o ócio com intenção negativa, pois o enxerga como improdutividade e prega que o indivíduo deve se entregar ao trabalho para ser considerado um 
sujeito de bem, que contribui para o progresso da sociedade como um todo.

Uma ideia da necessidade de ser produtivo é divulgada pela mídia como ideal de vida que deve ser buscado por todos, posto que é de interesse das classes dominantes que a classe trabalhadora continue ativa tanto para produzir quanto para consumir, movimentando a economia e mantendo a ordem social. É possível observar em telejornais e em comerciais ou telenovelas a imagem do ocioso ligada à margem da sociedade, associando esta condição, mesmo quando não por escolha, como no caso do desempregado, à de parasitas sociais.

Desempregados, subempregados e superexplorados passam por culpados e envergonhados por estarem em tais condições e assim buscam, através da venda de seu tempo, mal remunerado em grande parte das vezes, possuir recursos e alcançar status para serem aceitos na sociedade. Este é o caso em que Dejours (2005) classifica como a "banalização da injustiça social", uma vez que o trabalhador prefere se submeter às condições excessivas e precárias de trabalho, talvez não suficientes para seu próprio sustento, devido à pressão para trabalhar exercida direta e indiretamente pela sociedade. Uma relevante divulgação do sofrimento enfrentado por aqueles que não trabalham justificaria o sofrimento causado por péssimas condições de trabalho.

Existe, porém, outra concepção do que vem a ser ócio, que convive em nossa sociedade. No entanto, somente uma parcela da sociedade é permitida a desfrutar dela. Para mostrar este outro ponto de vista, Francileudo (2009, p. 211) afirma: "A vivência do ócio se relaciona a valores que estão ligados à dimensão da interioridade da pessoa como o bem-estar, o prazer, a diversão e a felicidade". Portanto, esta concepção de vivência do ócio diz respeito ao desfrute de um tempo necessário para que a felicidade se faça presente. Todos deveriam ter acesso a esse tempo, importante para o bem-estar de qualquer ser humano.

Por se tratar de uma experiência subjetiva, o ócio figuraria como um momento não cronometrado, posto não ser possível indicar o tempo necessário para essa experimentação. É impossível de ser padronizado, já que cada indivíduo significa de forma única suas experiências, pois algumas atividades consideradas prazerosas para uns podem não ser assim encaradas por outros.

Aquino e Martins (2007, p. 491), ao fazerem alusão a Aristóteles e a outros pensadores, parafraseiam que a vivência de ócio, sob esta concepção, está ligada à "percepção de felicidade". O "ócio, do ponto de vista individual, tem relação com a vivência de situações e experiências prazerosas e satisfatórias" (AQUINO; MARTINS, 2007, p. 491-492). O indivíduo, ao vivenciar atividades que lhe transmitam possibilidade de ócio, estará vivenciando experiências de 
prazer. Para a posterior avaliação da possível associação do consumo com o ócio, consideraremos este sentido: o ócio enquanto experiência prazerosa, a qual somente o próprio indivíduo pode caracterizar.

O indivíduo, em decorrência de avanços tecnológicos, pode vincular cada vez mais sua vida ao trabalho, através da Internet, com telefones celulares, tablets e demais aparelhos de comunicação que permitem que se trabalhe a qualquer hora do dia, ao dispor-se a serviço de obrigações decorrentes do cargo que ocupa. Martins et al. (2012, p. 227) ao descreverem que "o trabalho nos acompanha via aparelhos de última tecnologia que nos convocam em qualquer espaço e tempo" corroboram esta ideia, afirmando que o trabalho não está mais ligado ao tempo cronometrado pelo relógio de ponto, quando esta atividade pode ocorrer fora da empresa.

A partir da Revolução Industrial, o indivíduo tem dedicado grande parte de seu dia às atividades laborais em busca de obter mais recursos financeiros. O "mundo acelerado do progresso e do trabalho" (NOVAES, 2012, p. 14) trouxe consigo uma parafernália de objetos considerados indispensáveis à vida cotidiana, capazes de modificar tarefas, tornando-as intelectualizadas. Entretanto, em vez de haver tempo para a dedicação ao lazer e ao ócio, o indivíduo é atropelado por um turbilhão de afazeres. A tecnologia se vinculou ao trabalho no sentido de lhe dar mais possibilidades, que se constituiu em diminuição do trabalho braçal humano, através das automações das fábricas, para aumentar a vinculação humana a ele, permitindo seu acesso constante.

Soma-se a isso o fato de que o lazer também está relacionado à tecnologia de modo geral e à tecnologia de comunicação de forma mais específica. Parte dos relacionamentos sociais contemporâneos é mediada, ou seja, associados aos meios de comunicação, e não ocorrem da mesma forma pessoalmente. Percebe-se uma estratégia eficaz, do ponto de vista do patrão, em associar o trabalho ao principal objeto "voluntariamente" eleito para o lazer. Neste caso, grandes empresas não titubeiam em realizar um investimento oferecendo a seus empregados aparelhos de comunicação de última geração, alimentando sua satisfação com a empresa por uma possibilidade de acesso ao lazer; porém mascarando um real objetivo: vinculação constante do empregado a seu trabalho.

Isso pode mostrar como modos de viver são perpassados por ações ligadas ao trabalho que se desempenha. No século XIX, o controle era imposto como uma qualidade moral em que o indivíduo deveria dedicar parte de seu dia a atividades laboriosas com intuito de não ceder a maus pensamentos, destacando práticas higienistas exercidas pelo preenchimento do tempo, tais como prevenir que o adulto se entregasse à bebida e que as crianças fizessem 
"bobagens" (NOVAES, 2012).

Neste mesmo contexto, o qual chamaremos de Modernidade, o controle era exercido pela presença física de alguém que mantinha a ordem, através de estratégias como a arquitetura panóptica e a sanção normalizadora, práticas descritas e divulgadas por Foucault, em sua obra "Vigiar e Punir" (FOUCAULT, 1987).

Atualmente, não há um controle fisicamente presente, bem como não há necessariamente um confinamento em ambientes onde os superiores vigiam diretamente seus subordinados. O controle está presente e se exerce de forma diferenciada, onde cada pessoa se responsabiliza por suas ações e tornase o vigia de si mesmo. Ainda existem os olhares controladores, que estão internalizados e associados às tecnologias, fazendo com que o indivíduo aceite com naturalidade e até deseje estas sanções. Isso porque, para ser considerado produtivo e bem quisto na sociedade, deve-se dedicar a vida à produção e ao lucro e isso deve ser percebido, registrado, calculado e cronometrado através das tecnologias de comunicação (NOVAES, 2012).

Formulários divulgando produções, salários calculados de acordo com a produtividade e metas são algumas das estratégias usadas para substituir a presença física para se alcançar um controle desejado. Tais estratégias, divulgadas por Deleuze (1991), quando comparadas às supracitadas, encaixamse às características de fluidez da contemporaneidade, sendo tão cruéis e manipuladoras quanto às primeiras.

Diante disto, destaca-se uma dificuldade de percepção de momentos propícios para a vivência de experiências prazerosas desvinculadas do trabalho. O sucesso do consumo enquanto principal fonte de prazer contemporaneamente coroa esta associação, visto que vincula ainda mais os sujeitos a uma necessidade laboral para possibilitar o lazer, o prazer e o ócio.

\section{PRODUÇÃO E CONSUMO}

A partir da Revolução Industrial, o indivíduo passa a dedicar seu tempo às atividades laborais com intuito de gerar lucro, contribuindo para o aumento na produção e no consumo, acarretando problemas ambientais, em decorrência da extração indiscriminada e do mau uso dos recursos, além do acúmulo de resíduos industriais que poluem o meio ambiente (LEONARD, 2011; NOVAES, 2012).

Contudo, foi ainda no século XVI, a partir das "mudanças nos padrões de consumo da nobreza" (TASCHNER, 2010, p. 43) que iniciou a consolidação 
da considerada cultura de consumo contemporânea. Os nobres da época modificaram suas práticas de consumo, passando a gastar mais consigo mesmo do que com suas famílias, decorando suas residências, hospedando outros nobres e consumindo inclusive mais peças de vestuário.

A mudança nos padrões de consumo dos nobres, as grandes exposições internacionais do século XIX e o surgimento das primeiras lojas de departamento corroboraram o desenvolvimento da cultura de consumo. De acordo com Taschner (2010), é a partir daí que a cultura do consumo adquire significado diferente e nem mesmo a vida cotidiana seria da mesma forma de outrora: surge o consumismo.

Para Leonard (2011, p. 158), consumo diz respeito ao indivíduo "adquirir e utilizar bens e serviços para atender às necessidades". No que diz respeito ao consumismo, "refere-se à atitude de tentar satisfazer carências emocionais e sociais através de compras e demonstrar o valor pessoal por meio do que possui" (LEONARD, 2011, p. 158-159), ou seja, o consumismo estaria aliado a uma cultura da aparência. Não se pretende, contudo, com esta explanação, problematizar tal diferenciação, e sim destacar o prazer associado a ambas as práticas.

Bauman (2011, p. 83) dispõe que o consumo é uma "necessidade", somos todos consumidores, como apregoa o autor, "se pararmos de consumir, morremos". Ainda reitera que o consumismo se apresenta como um "produto social", uma vez que o indivíduo não deve apenas consumir aquilo que the é necessário para sobreviver, do ponto de vista das necessidades biológicas, não obstante se torna um ser consumista para ser aceito pela sociedade. A "alegria está toda nas compras" (BAUMAN, 2008, p. 28), pois o consumo de mercadorias tem como promessa a satisfação dos desejos do consumidor e a isso podemos associar sensações prazerosas semelhantes àquelas conseguidas pelos momentos de ócio.

Pinheiro, Rhoden e Martins (2010) consideram o consumismo como fonte de prazer e sofrimento simultaneamente, pois na sociedade contemporânea somos cada vez mais individualistas, buscando realizar desejos momentâneos, os quais estão atrelados ao consumo, enfatizando mais uma das ambivalências comuns ao tema em estudo.

As propagandas são estrategistas neste sentido, pois conseguem captar (e quem sabe até incutir) desejos nos potenciais consumidores. Não raro, trazem produtos com atributos humanos: um carro que é elegante, uma joia que é sensual, uma roupa que é conquistadora... Neste ponto é que se destaca a insatisfação humana associada ao consumo: o indivíduo consome produtos 
em busca de adquirir atributos divulgados para ele na mídia; todavia, depara-se com uma frustração de não conseguir este intento e passa a consumir cada vez mais em busca de suprir tais desejos. Essa busca parece ser pelo fato, como dispõe Sant'anna (2008, p. 57), de que contemporaneamente se alia consumo à felicidade, como se "o consumo tivesse necessariamente o dever de promover alegria".

Para Bauman, (2008, p. 29) "a sociedade de consumidores se baseia, em última instância, numa ilusão". Ao consumir, o indivíduo quer adquirir para si aquilo que está atribuído ao produto: beleza, juventude, status etc., mesmo conhecendo a impossibilidade disso. A mídia tem papel imprescindível nesta associação, veiculando opiniões e informações deturpadas que acabam por ludibriar até mesmo os consumidores mais informados.

\begin{abstract}
[...] o design por si só não consegue atrair o consumidor para o produto criado apenas com seus valores agregados, para isso se faz fundamental a participação da comunicação publicitária como conhecedor dos processos de veiculação e valoração das características do produto, criando no consumidor a vontade de possuir (KEGLER, 2013, p. 36-37).
\end{abstract}

Um exemplo da manipulação que a mídia pode promover em favor de ideais particulares já aconteceu nos EUA. Mesmo após a tragédia de 11 de Setembro, o presidente George W. Bush incentivou seus compatriotas a sair às compras, insinuando que esta seria uma forma de repúdio ao terrorismo. Bauman (2011, p. 84) relata que "A intenção da mensagem era conclamar os americanos a retomar a vida normal", posto ser o ato de fazer compras uma forma de aliviar tensões, conferir prazer e felicidade. Assim, isso torna um acontecimento tão emblemático em algo corriqueiro, como se a ação de adquirir bens fosse capaz de aplacar o sofrimento dos indivíduos frente ao atentado e às mortes decorrentes dele.

Brandini (2007) defende a ideia de que a produção e o consumo são práticas rituais das sociedades. Consumir seria uma "verdadeira prática ritual que representa a organização social e o universo simbólico dessas sociedades" (BRANDINI, 2007, p. 156). O indivíduo consome o significado que o produto traz em si e não sua materialidade. É possível perceber como a ideia de consumo e sua forma fazem parte dos modos de viver de um grupo e o singularizam.

Diante disso, percebe-se como as valorizações presentes no mundo contemporâneo acabaram por nos encaminhar à associação entre trabalho, 
consumo, ócio e lazer, aqui descritas como completamente imbricadas. Trabalha-se para consumir e divulga-se que não se pode deixar de trabalhar para não ser negativamente taxado na sociedade, como o ocioso. Experiências de ócio são possibilitadas pelo consumo, uma vez que o ócio improdutivo e meramente contemplativo já não é valorizado. Assim, a manutenção do sistema está garantida.

\section{ÓCIO E CONSUMO DE PRODUTOS DE MODA}

De acordo com Cuenca (2009), os estudos sobre o ócio trazem à tona a ideia aqui defendida: ócio e consumo possuem uma estreita relação, afinal a mídia procura passar, a partir de campanhas publicitárias, que a vivência de ócio é possível através de atividades de consumo, principalmente por conta das sensações despertadas no consumidor.

Não é à toa que o ato de consumir é considerada uma atividade de entretenimento, e "o ato da compra se converte em uma atrativa atividade social de entretenimento destinada a ocupar o tempo livre das pessoas" (ÁLVARES, 2006, p. 51). Além disso, consumir bens, de acordo com Sant' Anna (2008, p. 58) contribui para o aumento da auto-estima do indivíduo, uma vez que "um determinado produto pode fazer bem para o corpo e para a alma, tendo a capacidade de modificar o estado psicológico do consumidor".

O marketing está a "tirar proveito econômico das experiências valiosas de ócio" (CUENCA, 2009, p. 323); quer transformar atividades de consumo em experiências de ócio, desde a compra de alimentos até a uma viagem de férias, como se tudo fosse passível de propiciar vivências de ócio e das sensações associadas a esta experimentação. A divulgação do que se vende passa, mesmo que indiretamente, a informação de que se o consumidor não conseguir compreender a experiência como ócio, associando-a ao prazer, a culpa é dele e não do comércio, que lhe proporcionou esse momento.

Ainda segundo Sant'Anna (2008), a associação entre felicidade e consumo foi construída ao longo dos anos. No Brasil, desde a década de 1930, programas de rádio e a revista "O Cruzeiro" faziam alusão ao "antes" e "depois", ou seja, como os indivíduos estavam antes de consumirem determinado produto, no caso, infelizes, e como mudavam de espírito após o uso.

Em nossa sociedade, marcada pela exaltação ao consumo, podemos observar que os shoppings centers reúnem uma "síntese entre ócio,

1 el acto de la compra se convierte en una atractiva actividad social de entretenimiento destinada a ocupar el tiempo libre de las personas

2 sacar provecho económico de las experiencias valiosas de ocio 
entretenimento e consumo3" (ÁLVAREZ, 2006, p. 51). Nesses locais, são oferecidos produtos e serviços capazes de conceder aos frequentadores experiências de ócio que podem ser traduzidas na compra de um objeto; no uso de algum serviço, como por exemplo, um corte de cabelo no salão de beleza; ou até mesmo equipamentos de entretenimento como cinemas e teatros, além de áreas para diversão infantil com jogos e brinquedos. O indivíduo experimenta uma sensação de satisfação de todas as suas necessidades e, com o avanço da criminalidade, sente que tais locais the proporcionam um ambiente seguro e propício para realização de todos os seus desejos.

A moda resgata o consumo de diversas formas, ao apostar na dupla obsolescência dos produtos: a programada e a perceptiva. Todo produto possui um ciclo de existência, desde o momento que é concebido e elaborado, até seu descarte, o que se pode chamar de obsolescência programada, isto é, o tempo de durabilidade "real" do produto. Durante a sua existência e diante de sua manipulação, há um descarte natural que determina certa "validade" ao produto.

A obsolescência perceptiva, por outro lado, não se baseia no desgaste dos objetos, mas sim na programação externa daquilo o que deve mudar (e, portanto, ser descartado) de tempos em tempos. A mudança de comportamentos e o desenvolvimento de novas atrações são motivadores para que se elaborem novos produtos, estimulando-se que os adquiridos anteriormente, mesmo quando ainda perceptivelmente funcionais, sejam substituídos. A exemplo disso estão as divisões do ciclo de vendas da indústria varejista da moda, organizadas por meio da dualidade das estações do ano: primavera-verão e outono-inverno. Estas são taxas de repetição que envolvem dinâmicas do ciclo da moda (LOPES, 2012, 2014).

Desde sua contraditória proposta de identificação e de individualização, a moda carrega diversas promessas que acabam sendo satisfeitas, mesmo que momentaneamente, através do consumo, e por isso trazem a sensação de prazer. Ao adquirir produtos e exibi-los no espaço público, são associadas sensações únicas que servem de comunicação: status social e poder, gostos, preferências, desejos e identidades, a partir da liberdade que a oferta de produtos oferece. Ser capaz de escolher o que vai vestir é escolher que imagem passar à sociedade, o que se associa ao poder de ser aquilo o que se deseja (MARQUES, 2013).

Além disso, a moda pode ser expressão cultural, como se vê no reconhecimento, a partir da vestimenta, de certos grupos sociais como os "emos", os "rappers", ou os participantes dos "rolezinhos", todos frutos de uma cultura. 
Não somente pela moda, estes pares se associam, mas estas identificações acabam se tornando significantes para a socialização e compartilhamento de atividades prazerosas, de acordo com os gostos de cada grupo.

Outro exemplo de associações de sensações múltiplas aos momentos de consumo de produtos de moda é possível de ser visto no comportamento de algumas mulheres de alto poder aquisitivo na cidade de Cuiabá. Elas criaram uma forma de montar, de acordo com seus desejos, modelos exclusivos de bolsas, requisitados através de um responsável pela montagem. O serviço é complementado pelo atendimento, que oferece uma reunião frequente entre as consumidoras, momento no qual decidem pelo modelo que desejam, além de se encontrarem em um espaço onde podem conversar e relaxar (CARVALHO, 2011).

Essas experimentações são exemplos de vivências de prazer. O consumo desses produtos propicia experiências únicas, onde o ócio é representante de um momento de lazer, prazer e individualidade.

\section{CONSIDERACÕES FINAIS}

Ao considerar que uma experiência de ócio esteja atrelada a uma experiência de consumo, não podemos esquecer de que, em algum momento, foi necessário haver produção para que fosse possível a vivência do ócio. Nem sempre é possível produzir tudo aquilo de que o indivíduo necessita. Então, o consumo surge de forma a suprir esta deficiência, trazendo sensações de realização e plenitude.

Para se usufruir de atividades de consumo em um shopping center, momento que pode ser visto como expressão de ócio na contemporaneidade, responsável por restabelecer as forças gastas em atividades laborais, foi necessário produzir algo, a ser "trocado" pela verba necessária para se consumir: um carro ou o valor monetário da passagem de ônibus para o transporte até o centro comercial; os objetos que irá adquirir nas lojas; uma sessão de cinema com amigos ou familiares; uma refeição etc. Para que seja possível vivenciar tais experiências de ócio, é necessário que o indivíduo dedique parte do seu tempo às atividades laborais, fazendo com que a associação entre consumo e ócio seja ainda mais marcante, por ser a forma mais óbvia de obtenção de lazer e de restabelecimento das forças hoje em dia.

Mesmo que Cuenca (2009, p. 322-323) disponha que o ócio "não 
pode desaparecer no oceano indistinto dos atos de consumo 4", o indivíduo, para ter acesso a determinadas vivências de ócio, deve consumir bens ou serviços que servirão como propiciadores desses momentos. "Não somente consumimos nos centros comerciais, sem que todas nossas ações adotem a forma do consumo5" (CUENCA, 2009, p. 316), ou seja, quase tudo está contemporaneamente atrelado ao consumo.

O consumo não é única forma para alcançar momentos prazerosos de ócio. Porém, quando centrado na razão e não na paixão impulsiva, com um fim em si mesmo, (ÁLVAREZ, 2006) o consumo parece ser capaz de conferir ao consumidor sensações de prazer, mais temporárias que a fugaz sensação de realização com a ação de adquirir um produto.

No que se refere ao consumo de produtos de moda, toda a significação pessoal causada pela sensação de pertencimento a uma classe social pode vir a ser uma mensagem transmitida pela roupa que vestimos, o que incontestavelmente está atrelado a uma série de sensações prazerosas, além da sensação de bem-estar, possibilitada por uma aceitação social e pela diferenciação entre semelhantes. O consumo de produtos de moda mostra uma possibilidade da vivência de experiências prazerosas e reestabelecedoras, descritas por meio do ócio.

O consumo depende de ciclos estabelecidos pela indústria de moda, além de projeções percebidas pelo cruzamento de gostos, atitudes, comportamentos, necessidades etc., mediados por grupos sociais. Agindo de acordo com essa moderação, cada grupo permite vivenciar experiências que promovem o repouso de atividades laborais com o intuito de intervir nas relações que constroem. Promovendo encontros, discutindo ideias, socializando conhecimento, esses grupos consomem acima de tudo, perspectivas dessa interação. Tais perspectivas podem ser concretizadas através de produtos que materializam e solidificam as experiências que trocam através de momentos de lazer, consumo e ociosidade.

\section{REFERÊNCIAS}

ÁLVAREZ, Santiago. Contradicciones en las dinamicas del consumo actual: alienación, frustación e insostenibilidad. ADOZ: Revista de Estúdios de Ócio, Deusto, v. 29, p. 51-

$62,2006$.

4 no puede desaparecer en el océano indistinto de los actos de consumo

$5 \quad$ No solo consumimos en los centros comerciales, sino que todas nuestras acciones adoptan la forma del consumo 
AQUINO, Cássio Adriano Braz; MARTINS, José Clerton de Oliveira. Ócio, lazer e tempo livre na sociedade do consumo e do trabalho. Revista Mal-Estar e Subjetividade, Fortaleza, v. 7, n. 2, p. 479-500, 2007. Disponível em: <http:// hp.unifor.br/pdfs_notitia/1851.pdf>. Acesso em: 24 nov. 2013.

BAUMAN, Zygmunt. 44 cartas do mundo líquido moderno. Rio de Janeiro: Zahar, 2011.

Vida para consumo: a transformação das pessoas em mercadoria. Rio de Janeiro: Zahar, 2008.

BRANDINI, Valéria. Por uma etnografia das práticas de consumo.

Comunicação, Mídia e Consumo, São Paulo, v. 3, n. 9, p. 153-169, 2007.

Disponível em: <http://revistacmc.espm.br/index.php/revistacmc/article/ view/94/95>. Acesso em: 15 nov. 2013.

CARVALHO, Carla Gavilan. Pirata, mas classe A: sobre o consumo subalterno da pirataria de luxo. 2011. 136 f. Dissertação (Mestrado em Estudos de Cultura Contemporânea) - Instituto de Linguagens, Universidade Federal de Mato Grosso Cuiabá, 2011.

CUENCA, Jaime. Las experiências de ocio y el valor: la condición ejemplar del ocio en la sociedad de consumo. Revista de Humanidades, v. 24, n. 2, p. 315323, 2009. Disponível em: <http://www.unifor.br/images/pdfs/humanidades/ artigo6_2009.2.pdf>. Acesso em: 8 nov. 2013.

DEJOURS, Christophe. A banalização da injustiça social. Rio de Janeiro: Ed. FGV, 2005.

DELEUZE, Gilles. Conversações. Rio de Janeiro: Editora 34, 1991.

FOUCAULT, Michel. Vigiar e punir. Petrópolis: Vozes, 1987.

FRANCILEUDO, Francisco Antonio. Desvelando o valor do tempo para si: um estudo hermenêutico sobre o sentido ontológico do ócio. 2009. 244 f. Dissertação (Mestrado em Psicologia) - Universidade de Fortaleza, Fortaleza, 2009. Disponível em: <http://uolp.unifor.br/oul/ObraBdtdSiteTrazer. do?method=trazer>. Acesso em: 22 nov. 2013.

KEGLER, Alexandre José Muller. Comunicação publicitária e design no contexto da indústria cultural. Projética, Londrina, v. 4, n. 2, p. 29-38, jul./dez. 2013. 
LEONARD, Annie. A história das coisas: da natureza ao lixo, o que acontece com tudo que consumimos. Rio de Janeiro: Zahar, 2011.

LOPES, Humberto Pinheiro. Chafurdos das cópias: histórias da Moda com bandidos e mocinhas, nobres e plebeus. 2012. 133 f. Dissertação (Mestrado em Cultura Visual) - Faculdade de Artes Visuais, Universidade Federal de Goiás, Goiânia, 2012.

Chafurdos na moda: heróis e vilões na história das cópias. Goiânia: Editora UFG, 2014.

MARQUES, Camila. Moda, comunicação e sociedade: uma reflexão acerca dos sistemas de moda e suas possibilidades comunicacionais e contraculturais. Modapalavra, Florianópolis, v. 6, n. 11, p. 127-140, 2013.

MARTINS, José Clerton de Oliveira; AQUINO, Cássio Adriano Braz; SABÓIA, Iratan Bezerra; PINHEIRO, Adriana de Alencar Gomes. De Kairós a Kronos: metamorfoses do trabalho na linha do tempo. Cadernos de Psicologia Social do Trabalho, São Paulo, v. 15, n. 2, p. 219-228, 2012. Disponível em: $<$ http://pepsic.bvsalud.org/scielo.php?script=sci_arttext\&pid=S151637172012000200005\&lng=pt\&tlng=pt>. Acesso em: 24 nov. 2013.

NOVAES, Adauto. As aventuras de uma palavra maldita. In: Mutações: elogio à preguiça. São Paulo: Edições SESC SP, 2012. p. 11-27.

PINHEIRO, Kátia Flores; RHODEN, leda; MARTINS, José Clerton de Oliveira. A experiência do ócio na sociedade hipermoderna. Revista Mal Estar e Subjetividade, Fortaleza, v. 10, n. 4, p. 1131-1146, 2010. Disponível em <http://pepsic.bvsalud.org/scielo.php?script=sci_arttext\&pid=S1518$61482010000400004 \&$ Ing=pt\&tlng=pt>. Acesso em: 24 nov. 2013.

SANT'ANNA, Denize Bernuzzi. Consumir é ser feliz. In: OLIVEIRA, Ana Claudia; CASTILHO, Kathia (Org.). Corpo e moda: por uma compreensão do contemporâneo. Barueri: Estação das Letras e Cores, 2008. p. 57-66.

TASCHNER, Gisela. Comunicação, sociedade e imaginários do consumo. Comunicação, Mídia e Consumo, São Paulo, v. 7, n. 20, p. 37-57, 2010. Disponível em <http://revistacmc.espm.br/index.php/revistacmc/article/ view/204/202>. Acesso em: 20 nov. 2013. 


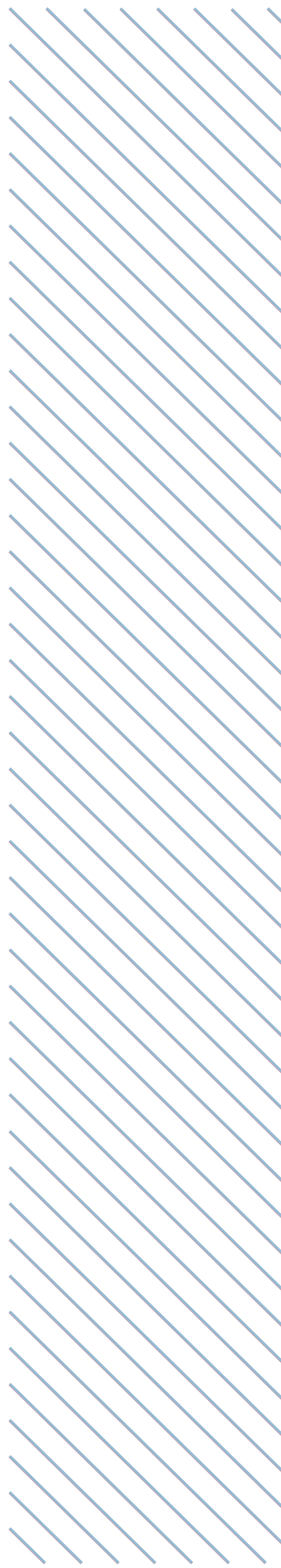

